\title{
Critical Factors Involved in the Determination of the Optimal Concentration of Ophthalmic Anti-infective Compounded Drugs
}

Anxo Fernández-Ferreiro ${ }^{1,3,4^{*}}$, Miguel González-Barcia ${ }^{3,4}$, Gil-Martínez $\mathbf{M}^{5,6}$, Blanco-Méndez $\mathrm{J}^{1,2}$, Luaces-Rodriguez $\mathrm{A}^{1}$, Victoria Díaz Tome ${ }^{1}$, Lamas MJ ${ }^{3,4}$ and Otero-Espinar FJ ${ }^{1,2}$

${ }^{1}$ Pharmacy and Pharmaceutical Technology Department, Faculty of Pharmacy, University of Santiago de Compostela (USC), Spain

${ }^{2}$ Industrial Pharmacy Institute, University of Santiago de Compostela (USC), Spain

${ }^{3}$ Pharmacy Department, Xerencia de Xestión Integrada de Santiago de Compostela, SERGAS, Santiago de Compostela, Spain

${ }^{4}$ Clinical Pharmacology Group, Health Research Institute of Santiago de Compostela (IDIS-ISCIII), Spain

${ }^{5}$ Ophthalmology Department, Xerencia de Xestión Integrada de Santiago de Compostela, SERGAS, Santiago de Compostela, Spain

${ }^{6}$ Institute Ophthalmology Gomez Ulla. Santiago de Compostela, Spain

\section{Introduction}

Physiopathology characteristics of the eye make generally the treatment of the ocular surface illnesses difficult. In addition to the etiology, many times there is not any ocular commercial treatment available due to economical or stability issues. In this cases compounded drug are the alternative $[1,2]$.

In ophthalmic pharmaceutical compounding, it is common to use parenteral formulations for the preparation of ophthalmic drugs by dissolution or dilution in eye compatible buffers. However, parenteral drugs are not designed for or adapted to ocular administration, so they can cause no desirable effects in the eye. On the other hand, we barely have ocular toxicity and dose-respond studies of these drugs. Therefore, the concentrations utilised are chosen based on previous results and clinical experience gathered over the years [3].

Moreover, the poor adaptation to the route and the tendency of using simple formulations produce low efficiency systems, since they have a low permanence in the surface eye owing to the effective precorneal clearance mechanisms [4]. In order to achieve therapeutic concentrations, ophthalmologists prescribe eye drops with high doses of drugs, using very frequent instillations for extended periods of time. This may cause great discomfort among patients that often results in a reduction in treatment adherence with the necessity of hospitalization in order to obtain correct compliance and recovery [5].

The manifestation of ocular toxic effects is quite common and can be caused by commercial medicines as well as by compounded drugs. This can occasionally imply the interruption of the treatment. There are tons of pharmacological groups of drugs for ocular route with well-known potential toxicity, like NSAIDs or prostaglandin analogues for glaucoma [6]. These medicines, despite having gone through a strict control by the regulatory agencies, have sometimes significant toxicities. Another therapeutic group with well-known ocular toxicity are the compounded drugs named as reinforced eye drops of antibiotics. These eye drops are used in the treatment of complex bacterial keratitis in which it is necessary topic antibiotics no commercially available or high concentrations of antibiotics which treble the commercial concentrations [7].

It is difficult to achieve effective concentrations of drugs on the ocular surface for long periods due to strong precorneal clearance. Different technologies have been tested to increase ocular retention time, standing out the ones based onthe use of mucoadhesive polymers, smart hydrogels and nanotechnology [8]. Bioadhesive polymers increases the eye surface residence time by means unspecific or specific interactions with the ocular mucosae prolong the residence time [9]. In situ stimulus hydrogels are utilised due to their ability of modifying their consistence and structure when they are exposed to

\section{Publication History:}

Received: July 10, 2016

Accepted: December 26, 2016

Published: December 28, 2016

\section{Keywords:}

Ophthalmic, Drug, Cyclodextrins, Macromolecules

external stimulus [9]. These formulations gelled in the eye surface by effect of a specific stimulus forming a hydrogel film that releases the drug [10]. The ocular surface provides properties (i.e. tear ion concentration, $\mathrm{pH}$ or temperature) which facilitate the gelling of some stimuli-responsive polymers that otherwise are in sol forms which can easily be administered into the eye $[8,11,12]$. Finally the nanocarriers can enhance the bioavailability of ophthalmic formulations by means the improvement of the drug release properties, the surface permanence and the drug penetration into the eye tissues.

On the other hand, poor aqueous solubility of some drugs complicates their ocular administration. Hence, a challenge in the ocular formulation is to achieve the incorporation oflipophilic drugs in ocular systems for pathologies with not many or none available commercial alternatives. In order to reach that, it is indispensable to increase solubility in water [13]. Cyclodextrins technology, nanosuspensiones, polymeric micelles or the use of cosolvents or hydrophilic polymers are useful pharmaceutical tools that aid in the formulation of poorly aqueous soluble drugs [14].

The mentioned factors are just some of the ones that must be assessed when designing a new ophthalmic formulation. For instance, it is also necessary to determine optimal concentration of an antiinfective when designing a new formulation for ocular infections.

\section{Minimum Inhibitory Concentration in Ocular Opical Formulations}

Drug concentrations used in the current treatment of ocular infections that affect anterior chamber are in revision. Efficiency of

"Corresponding Author: Prof. Francisco Javier Otero Espinar, Pharmacy and Pharmaceutical Technology Department, Faculty of Pharmacy, University of Santiago de Compostela (USC), Spain, E-mail: francisco.otero@usc.es

Citation: Fernández-Ferreiro A, González-Barcia M, Gil-Martínez M, BlancoMéndez J, Luaces-Rodriguez A, et al. (2016) Critical Factors Involved in the Determination of the Optimal Concentration of Ophthalmic Anti-infective Compounded Drugs. Int J Clin Pharmacol Pharmacother 1: 122. doi: https://doi. org/10.15344/2016/2456-3501/122

Copyright: (c) 2016 Fernández-Ferreiro et al. This is an open-access article distributed under the terms of the Creative Commons Attribution License, which permits unrestricted use, distribution, and reproduction in any medium, provided the original author and source are credited. 
Citation: Fernández-Ferreiro A, González-Barcia M, Gil-Martínez M, Blanco-Méndez J, Luaces-Rodriguez A, et al. (2016) Critical Factors Involved in the Determination of the Optimal Concentration of Ophthalmic Anti-infective Compounded Drugs. Int J Clin Pharmacol Pharmacother 1: 122. doi: https://doi. org/10.15344/2016/2456-3501/122

Page 2 of 5

topical treatments with antibiotic concentrations lower than usual has been reported by numerous authors.

Effective concentration of antimicrobials depends whether the concentration of anti-infectives exceeds Minimum Inhibitory Concentration (MIC). MIC is expressed in $\mathrm{mg} / \mathrm{L}$ or $\mu \mathrm{g} / \mathrm{mL}$ and it is defined as the concentration of an antimicrobial that will inhibit the microorganism growth of 105 colony-forming units (CFU). MICs are regularly established by the European Committee on Antimicrobial Susceptibility Testing (EUCAST MIC breakpoints)[15].

Cut-off points are determined in function of based on antimicrobial concentrations reached in plasma. For this reason, the committees establish the limits and classify microorganisms as Susceptible, Intermediate and Resistant supposing a systemic administration. When deciding the therapeutic dose of an anti-infective, the main focus might be their tolerability and then in their capacity of exceeding plasmatic MICs [16]. The election of dosing intervals follows a similar approach, because it is based on the period of time that plasmatic concentration exceeds MIC. It is considered that some drugs do not reach the same concentrations in tissues as in plasma. Hence, regardless of the conditions addressed above, it is recommendable to reach plasmatic concentrations four or five times higher than the MIC of the microorganism during the entire interval [17]. It is no possible to apply the same defined cut-off pointsfor classifying microorganisms as susceptible or resistant to ocular pharmacology. The reason is that concentrations achieved with topical administrations differ from the ones achieved in the target site with systemic administrations [18].

So far, antibiotics are the group of anti-infectives more settled and in which pharmaco-therapeutic strategies based on pharmacokineticpharmacodynamic parameters (PK/PD) are more developed. The first parameter to consider in order determining therapeutic efficiency is the inhibitory ratio, which is obtained dividing maximum serum concentration $(\mathrm{Cmax})$ by the MIC. This parameter is valid for aminoglycosides, fluoroquinolones and $\beta$-lactam antibiotics $[19,20]$ $[21,22]$. The second one is the rate represented by under the curve area divided by minimum inhibitory concentration (AUC/MIC), which is useful for aminoglycosides, fluoroquinolones and vancomycin. The third parameter is the time at which serum concentrations exceed MIC ( $>$ MIC) which is used for penicillins and cephalosporins $[23,24]$.

Aminoglycosides are concentration dependent antibiotics and bactericide effect increases as antibiotic concentration raises. It is considered that inhibitory ratios between 8 and 10 are appropriate to reach therapeutic success. However, the most suitable parameter for therapeutic success is the rate AUC/MIC [20]. In addition, aminoglycosides show an evident post-antibiotic effect in vitro e in vivo in experimental models of infection.

At the moment there are not conclusive studies about permanency and concentrations reached on the ocular surface for anti-invectives as aminoglycosides. The volume of the precorneal lacrimal film is approximately $7-10 \mu \mathrm{l}$, which may increase up to $30 \mu \mathrm{L}$ before blinking after the instillation [25]. Renewal velocity (Q) of tear film is $0.5-2.2 \mu \mathrm{l} / \mathrm{min}$ (mean $1.2 \mu \mathrm{l} / \mathrm{min}$ )[26]. Therefore, time of renewal of the lacrimal film $(\mathrm{T})$ is determined by the following equation: $\mathrm{T}=\mathrm{V} / \mathrm{Q}$ and its value is 5 minutes. Based in this considerations Figure 1 shows are presentation of the theoretical ocular surface concentration of amikacin versus time obtained by the instillation of one drop (20 $\mu \mathrm{l})$ of a solution of amikacin containing $33 \mathrm{mg} / \mathrm{ml}$. After instillation in the eye surface, which contains $7 \mu$ of tear fluid, it is reached an instantaneous concentration of $25.00 \mathrm{mg} / \mathrm{l}$. The first blinking reduces eye drop volume to $7-10 \mu \mathrm{l}$ (what it is left on the corneal surface) eliminating about $40-60 \%$ of the drug dose. Henceforth, concentration reduction will be defined by lacrimal clearance $(1.2 \mu \mathrm{l} /$ min). Furthermore, it is necessary to know that Pseudomonas spp are generally considered susceptible to amikacin with MICs lower than 8 $\mathrm{mg} / \mathrm{L}$ [15]

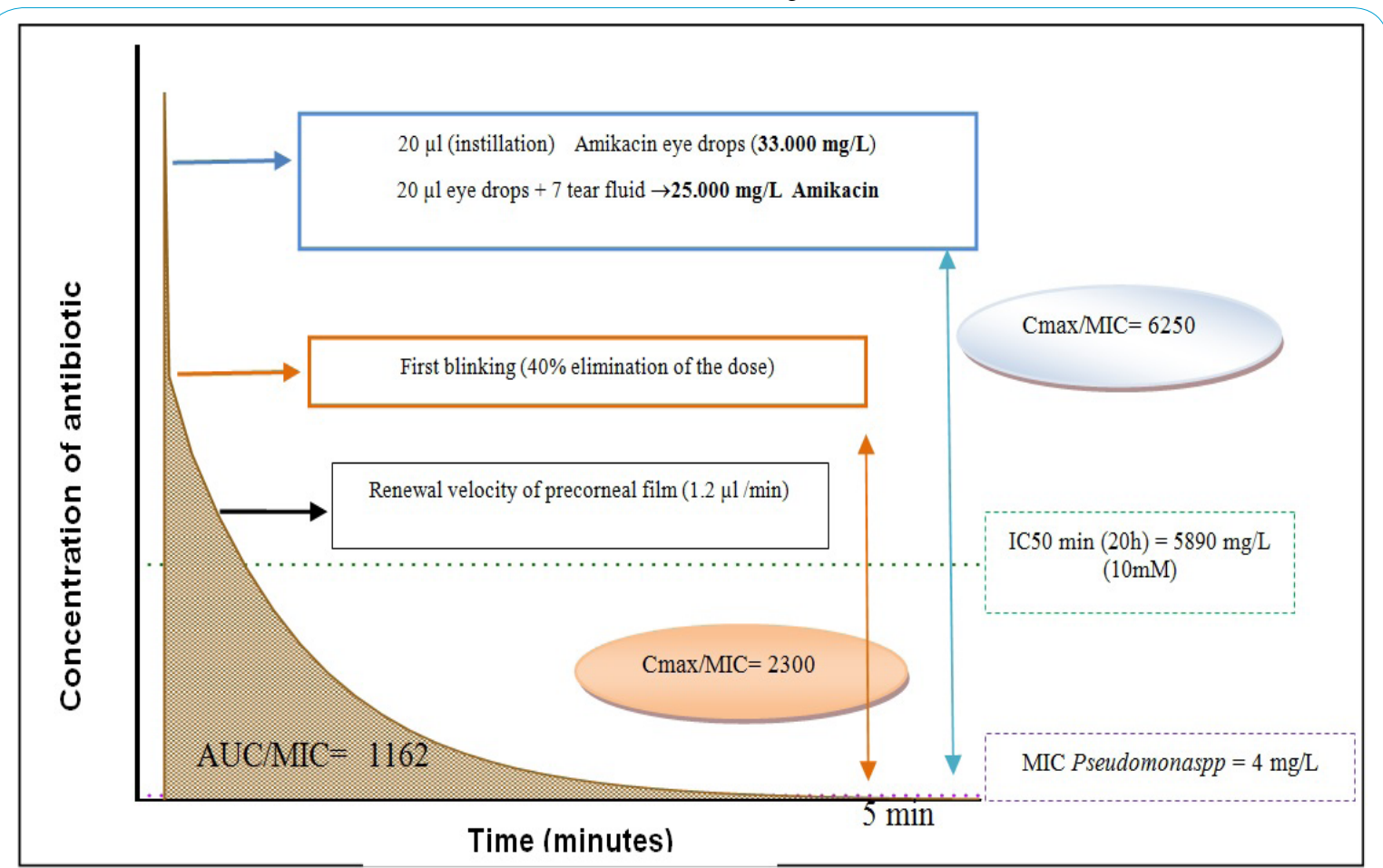

Figure 1: Theoretical evolution of the concentration of one drop of amikacin $33 \mathrm{mg} / \mathrm{ml}$ throughout time (5 minutes). 
Citation: Fernández-Ferreiro A, González-Barcia M, Gil-Martínez M, Blanco-Méndez J, Luaces-Rodriguez A, et al. (2016) Critical Factors Involved in the Determination of the Optimal Concentration of Ophthalmic Anti-infective Compounded Drugs. Int J Clin Pharmacol Pharmacother 1: 122. doi: https://doi. org/10.15344/2016/2456-3501/122

Page 3 of 5

This means amikacin eye drops normally used in clinical practice contain a concentration of drug which represents an inhibitory ratio of 6250 after instillation. Therefore, the initial ratioexceed thousands of times the requirement for efficiency of aminoglycosides (Graph also shows the lowest value of IC50 [27]). Concentrations reached on the ocular surface are instantaneous and the drug remain on the ocular surface just lasts minutes, making impossible to achieve properly rates AUC/MIC. An area of $4560 \mathrm{mg} \mathrm{l}^{-1} \mathrm{~min}^{-1}$ has been calculated in our estimation. Therefore, the rates obtained are greater than 1000 and exceed the values recommended for therapeutic success. High concentrations in eye drops are usually used to increase the AUC/MIC and to improve penetration of drugs through corneal epithelium with the aim of exceeding the MIC of the microorganism. Nevertheless, most of these eye drops are used for superficial infections in which epithelial damage is observed and so stroma is completely exposed [28].

It is necessary to considerate also that the physio-pathology conditions of the eye and the characteristics of the eye drops can modify also the drug concentration. High precorneal clearance is produced by some pathologies and also strong lacrimation can be induced by $\mathrm{pH}$ or osmolarity of the drugs increasing the drug elimination shorting their permanence on the ocular surface [29]. On the other hand, half-life of some drugs in the eye can been incremented if interact with the components of the surface or if the drug diffuses to the cornea or conjunctive. For instance, it has been demonstrated that mean concentrations of ofloxacin measured in the lacrimal film four hours after topical administration were over $2 \mu \mathrm{g} /$ $\mathrm{ml}$, which is the minimum concentration of ofloxacin for inhibition "in vitro" of the $90 \%$ (MIC 90) of more common bacterial streams in the eyes. Another study shows that the topical administration of Oftacilox ${ }^{\oplus}$, one drop each 15 minutesin the first hour and each hour in the next 10 hours, provides a mean concentrations of ciprofloxacin in the stroma of $5.28 \mu \mathrm{g} / \mathrm{g}$ of tissue [30,31].

Moreover, it is necessary to make more complex considerations fordrugsthat needs todiffuse through epithelial barrier, where multiple factors may be involve (degree of ionization, drug binding to proteins, ocular pigmentation oroptimization of instilled volume). Having seen the factors needed to take into account and having made clear that MICs used normally in antibiograms are not the ones they should be used for determining susceptibility or resistance, now it is necessary to know the target site of the drugs (ocular surface, anterior chamber or posterior chamber).

\section{Penetration of Drugs through Cornea}

The anatomy, physiology and biochemistry of the eye make it inherently impermeable to foreign substances. The challenge in the ophthalmic formulations is to dodge ocular barriers without causing permanent damage. Drug's absorption rate by topical route is conditioned by physiologic limitations, being one the cornea. The cornea is a tissue optically transparent which works as the main element of refraction. Corneal density ranges from 0.5 to $0.7 \mathrm{~mm}$ and is thicker in the centre than in the limbo [32].

Epithelium constitutes approximately the tenth part of the total thickness of the cornea and is in contact with the lacrimal film. It works as a barrier for transport of ions due to the presence of tight junctions in epithelial cells which serve as a selective barrier for small molecules, avoiding the diffusion of macromolecules by transcellular pathway. The most superficial epithelial cells have a half-life of just a few days and they do not leave scars when damaging due to their great regeneration capacity. The Bowman's membrane is an acellular layer locatedover the stroma and it does not regenerate when damaging. The stroma is a high hydrophilic layer compounded by keratocytes which produce collagen and extracellular ground substances and in overall constitutes the $85 \%$ of the total corneal thickness. Pre-descemet o Dua membrane has just been discovered and its function is still establishing. It is in close contact with Descemet membrane which contacts with endothelium basement membrane. The endothelium is responsible of maintaining cornealhydration and transparency. It only has a layer of hexagonal cells which are gradually reduced with age due to their incapacity of regeneration $[33,34]$.

Drugs used in ophthalmology should be lipophilic in order to penetrate through the epithelium and endothelium and also hydrophilic to be able to go through stroma. Molecular weight and structure is also important. Lipophilic compounds go through phospholipid bilayers by diffusion, regardless of molecular size and structure. On the contrary, the hydrophilic ones go through proteins and globular pores. Hydrophylic molecules with molecular weights lower than $100 \mathrm{Da}$ go through cornea without any difficulty whereas the ones with molecular weighs bigger than $500 \mathrm{Da}$ do no cross the cornea. Absorption of compounds can be facilitated increasing the concentration of the formulations which entail the creation of a concentration gradient between the lacrimal film and the corneal epithelium. This is the basis of the application of fortified eye drops [35]. On the other hand, only lipophilic non-ionized drugs can go rapidly until the stroma. However, ionized and non-ionized forms must co-exist to achieve complete penetration. Once in the stroma, the ionization of the drug improve their distribution in this area, but for diffuses across the endothelia is necessary to revert to the non-ionized form. Therefore, drugs which are totally ionized or non-ionized will not go through the cornea. Moreover, the use of hypotonic solutions, substances that modify the epithelium permeability (i.e surfactant agents) or vehicles that increases the residence time in the ocular surface, can promote the diffusion of the drug in the cornea [35].

MIC should be interpreted keeping in mind pharmacokinetic and pharmacodynamic information (PK/PD)(18). A key factor is to know the site the drug must reach (epithelium, stroma, anterior chamber or posterior chamber) and afterwards it is necessary to study drug concentrations in each one of these places after topical administrations to exceed the MIC [36,37].

Concentrations of antifungal drugs detected in the different parts of the eye after topical administration differ depending of the authorand the methodology used is quite varied (different dose regimen, different animals, different determinations techniques, etc.) [38].

In the following Table 1 it is shown some of the concentrations achieved by the most common antifungal eye drops in the anterior chamber [39].

Once known concentration achieved by the anti-infectives in the site target, it is necessary to know the susceptibility of the microorganism in order to know if the concentrations used are the appropriate ones. In Table 2 it is shown some of the antibiotics most used in therapeutics and MICs of some of the most important microorganisms.

Considering all the factors mentioned above, it is essential to take in consideration the importance of PK/PD relations when interpreting MICs, primarily in topical formulations. In this context, 
Citation: Fernández-Ferreiro A, González-Barcia M, Gil-Martínez M, Blanco-Méndez J, Luaces-Rodriguez A, et al. (2016) Critical Factors Involved in the Determination of the Optimal Concentration of Ophthalmic Anti-infective Compounded Drugs. Int J Clin Pharmacol Pharmacother 1: 122. doi: https://doi. org/10.15344/2016/2456-3501/122

Page 4 of 5

\begin{tabular}{|c|c|c|c|}
\hline Antifungical Drug & Presentation Available & Concentration in Vitreous Humour & REF \\
\hline Amphotericin B & Amphotericin B deoxycholate eye drops (Fungizone $\left.{ }^{\star}\right) 1.5 \mathrm{mg} / \mathrm{ml}$ & No penetrates without prior epithelial debridement. & {$[40,41]$} \\
\hline Natamycin & Natacyn $50 \mathrm{mg} / \mathrm{ml}$ & No penetrates without prior epithelial debridement & {$[42]$} \\
\hline Econazole & Aurazole $^{\infty} 20 \mathrm{mg} / \mathrm{ml}$ & $0.504 \mu \mathrm{g} / \mathrm{ml}$ & {$[43]$} \\
\hline Fluconazole & Fluconazol eye drops $2 \mathrm{mg} / \mathrm{ml}$ & $7.13 \mu \mathrm{g} / \mathrm{ml}$ & {$[44]$} \\
\hline Voriconazole & Voriconazole eye drops $\left(\right.$ Vfend $\left.^{\circledR}\right) 10 \mathrm{mg} / \mathrm{ml}$ & $6 \mu \mathrm{g} / \mathrm{ml}$ & {$[45]$} \\
\hline
\end{tabular}

Table 1: Concentration reached by antifungal eye drops in vitreous humor.

\begin{tabular}{|c|c|c|c|c|c|}
\hline & Amphotericin & Natamycin & VORICONAZOLE & FLUCONAZOLE & ECONAZOLE \\
\hline Aspergillus spp & $0.09 \sim \geq 32$ & $1 \sim 64$ & $0.25 \sim 8$ & $32 \sim \geq 256$ & 3.12 \\
\hline Fusarium spp & $0.06 \sim \geq 32$ & $2 \sim 32$ & $0.25 \sim 16$ & $0.001 \sim \geq 256$ & 0.053 \\
\hline Candida albicans & $0.001 \sim 160$ & - & $0.001 \sim 16$ & $0.03 \sim \geq 256$ & $0.25 \sim 100$ \\
\hline
\end{tabular}

Table 2: MICs of most common pathogenic agents in fungal keratitis $(\mu \mathrm{g} / \mathrm{ml})$.

Considering all the factors mentioned above, it is essential to take in consideration the importance of $\mathrm{PK} / \mathrm{PD}$ relations when interpreting MICs, primarily in topical formulations. In this context, it is important to know the place the drug must reach. For superficial infections, drug concentrations used are typically bigger than MICs whereas if the infection is in the anterior or posterior chamber the penetration could not be enough to achieve concentrations over the MIC. Therefore, a fungus could be susceptible to a certain drug in superficial keratitis and resistant to the same drug in infections in the anterior/posterior chamber. On the other hand, it is essential to know the pharmacodynamic considerations of each drug. Some antifungal drugs, such as amphotericin, are concentration dependent which implies that a dose increase is proportional to microorganism destruction. The predictive parameter of success in this case is to achieve Cmax/MIC ratios bigger than 10. Moreover, it is important to highlight the existence post-antifungal effect (PAFE) of some drugs that could achieve values as far as 20 hours for the amphotericin. On the contrary, fluconazole is time dependant which means that the efficiency of the treatment depend on the length of time that drug concentration exceed the MIC [37]. It is also necessary to take into account that a lot of antimicrobials have been proved to be active with sub-inhibitory concentrations due to their capacity to modify superficial properties of microorganisms interfering in their adhesion capacity to the cells surface an so decreasing their pathogenicity [54].

Many authors and even somedata sheet of some ophthalmic anti-infectives [55] continue to use the term Susceptible/Resistant only based on MIC [56]. The classification of a microorganism as Susceptible or Resistant to a certain drug can provoke therapeutic misunderstandings. These misinterpretations could induce unnecessary prescriptions of eye drops with high drug concentrations or indications of short dose intervals that could be toxic for the eye [57] Therefore, it is crucial to study in detail all the parameters that can affect the therapeutic efficiency of these drugs [58].

Although a lot of progress has been made in this area, the invasive methodology required for this studies makes that a limited number of patientswere studied and slows down the investigation [59].

An additional effort must be made by pharmaceutical research in order to develop more effective and safe ophthalmic anti-infective drug delivery systems. The interdisciplinary collaboration between pharmacists, microbiologists and ophthalmologists will be key factors for future and fruitful research can clarify many of the issues raised and still unresolved in the anti-infective ophthalmic drug therapy.

\section{Competing Interests}

The authors declare that they have no competing interests.

\section{References}

1. Ferreiro AF, Barcia MG, Martínez MG, Méndez JB, Espinar FJO, et al. (2016) Current use of Antifungal Eye Drops and How to Improve Therapeutic Aspects in Keratomycosis. Fungal Genom Biol 6:130.

2. Fernández-Ferreiro A, Gonzalez-Barcia M, Gil-Martinez M, Alba Dominguez J, Otero Espinar FJ (2014) Use of fortified eye drops on eye infections. Atencion Farmaceutica 16: 216-219.

3. Ayaki M, Iwasawa A, Niwano Y (2012) In vitro assessment of the cytotoxicity of six topical antibiotics to four cultured ocular surface cell lines. Biocontrol Sci 17: 93-99.

4. Short BG (2008) Safety evaluation of ocular drug delivery formulations: techniques and practical considerations. Toxicol Pathol 36: 49-62.

5. Sleath B, Blalock S, Covert D, Stone JL, Skinner AC, et al. (2011) The relationship between glaucoma medication adherence, eye drop technique, and visual field defect severity. Ophthalmology 118: 2398-2402.

6. Fernández-Ferreiro A, Santiago-Varela M, Gil-Martínez M, Parada TG-C Pardo M, et al. (2015) Ocular safety comparison of non-steroidal antiinflammatory eye drops used in pseudophakic cystoid macular edema prevention. Int J Pharm 495: 680-691.

7. Dehghani A, Fazel F, Akhlaghi MR, Ghanbari H, llanloo MR et al. () Fortified Cefazolin-Gentamicin versus Fortified Vancomycin-Ceftazidime Drops for Treatment of Bacterial Corneal Ulcers. J Ophthalmol 13: 381 386.

8. Pawar P, Kashyap H, Malhotra S, Sindhu R (2013) Hp-ß-CD-Voriconazole In Situ Gelling System for Ocular Drug Delivery: In Vitro, Stability, and Antifungal Activities Assessment. BioMed Res Int 2013: 341218.

9. Alvarez-Lorenzo C, Blanco-Fernandez B, Puga AM, Concheiro A (2013) Crosslinked ionic polysaccharides for stimuli-sensitive drug delivery. Adv Drug Deliv Rev 65: 1148-1171.

10. Fernández-Ferreiro A, González Barcia M, Gil-Martínez M, Vieites-Prado A, Lema I, et al. (2015) In vitro and in vivo ocular safety and eye surface permanence determination by direct and Magnetic Resonance Imaging of ion-sensitive hydrogels based on gellan gum and kappa-carrageenan. Eur J Pharm Biopharm 94: 342-351.

11. Gupta H, Velpandian T, Jain S (2010) lon- and pH-activated novel in-situ gel system for sustained ocular drug delivery. J Drug Target 18: 499-505. 
Citation: Fernández-Ferreiro A, González-Barcia M, Gil-Martínez M, Blanco-Méndez J, Luaces-Rodriguez A, et al. (2016) Critical Factors Involved in the Determination of the Optimal Concentration of Ophthalmic Anti-infective Compounded Drugs. Int J Clin Pharmacol Pharmacother 1: 122. doi: https://doi. org/10.15344/2016/2456-3501/122

Page 5 of 5

12. Fernández Farrés I, Norton IT (2014) Formation kinetics and rheology of alginate fluid gels produced by in-situ calcium release. Food Hydrocoll 40 76-84

13. Fernández-Ferreiro A, Fernández Bargiela N, Varela MS, Martínez MG Pardo M, et al. (2014) Cyclodextrin-polysaccharide-based, in situ-gelled system for ocular antifungal delivery. Beilstein J Org Chem10: 2903-2911.

14. Otero Espinar FJ, Torres-Labandeira JJ, Alvarez-Lorenzo C, BlancoMéndez J (2010) Cyclodextrins in drug delivery systems. J Drug Del Sci Tech 20: 289-301.

15. Kahlmeter G, Brown DFJ, Goldstein FW, MacGowan AP, Mouton JW, et al. European Committee on Antimicrobial Susceptibility Testing (EUCAST) Technical Notes on antimicrobial susceptibility testing. Clin Microbiol Infect 12: 501-503.

16. Leclercq R, Cantón R, Brown DF, Giske CG, Heisig P, et al. (2013) EUCAST expert rules in antimicrobial susceptibility testing. Clin Microbiol Infect 19 141-160.

17. Levison ME, Levison JH (2009) Pharmacokinetics and pharmacodynamics of antibacterial agents. Infect Dis Clin North Am 23: 791-815, vii.

18. Guideline on the evaluation of medicinal products indicated for treatment of bacterial infections. 15 December 2011 CPMP/EWP/558/95 rev 2 Committee for Medicinal Products for Human Use (CHMP).

19. Drusano GL, Goldstein FW (1996) Relevance of the Alexander Project: pharmacodynamic considerations. J Antimicrob Chemother 38 Suppl A 141-154.

20. Moore RD, Lietman PS, Smith CR (1987) Clinical response to aminoglycoside therapy: importance of the ratio of peak concentration to minimal inhibitory concentration. J Infect Dis 155: 93-99.

21. Forrest A, Nix DE, Ballow CH, Goss TF, Birmingham MC, et al. (1993) Pharmacodynamics of intravenous ciprofloxacin in seriously ill patients. Antimicrob Agents Chemother 37: 1073-1081.

22. Suárez C, Gudiol F (2009) [Beta-lactam antibiotics]. Enferm Infecc Microbiol Clin 27: 116-129.

23. Craig WA, Vogelman B (1984) Changing patterns of hospital infections: implications for therapy. Changing concepts and new applications of antibiotic pharmacokinetics. Am J Med 77: 24-28.

24. Craig WA (1998) Pharmacokinetic/pharmacodynamic parameters: rationale for antibacterial dosing of mice and men. Clin Infect Dis 26: 1-10.

25. Lux A, Maier S, Dinslage S, Süverkrüp R, Diestelhorst M (2003) A comparative bioavailability study of three conventional eye drops versus a single lyophilisate. Br J Ophthalmol 87: 436-440

26. Eter N, Göbbels M (2002) A new technique for tear film fluorophotometry. Br J Ophthalmol 86: 616-619.

27. Fernandez-Ferreiro A, Santiago-Varela M, Pardo M, Barcia MG, PineiroCes A, et al. (2014) Effect of diferent fortified antibiotic eye drops on human eye drops on human and bovine corneal cells in vitro. Invest Ophthalmol Vis Sci 55: 4891-4891.

28. Yuan X, Hua X, Wilhelmus KR (2010) The corneal expression of antimicrobial peptides during experimental fungal keratitis. Curr Eye Res 35: 872-879.

29. Aslan Bayhan S, Bayhan HA, Muhafız E, Bekdemir S, Gürdal C (2015) Effects of osmoprotective eye drops on tear osmolarity in contact lens wearers. Can J Ophthalmol 50: 283-289.

30. Ficha técnica OFTACILOX $3 \mathrm{mg} / \mathrm{ml}$ colirio en solución [Internet].

31. Seitz B, Hayashi S, Wee WR, LaBree L, McDonnell PJ (1996) In vitro effects of aminoglycosides and fluoroquinolones on keratocytes. Invest Ophthalmol Vis Sci 37: 656-665

32. Gonzalez Barcia M (2011) Formulación Magistral en Oftalmología. In Aspectos prácticos de la farmacotécnia en un servicio de farmacia [Internet]. Galpagar: Master Line Prodigio.

33. Dua HS, Faraj LA, Said DG, Gray T, Lowe J (2013) Human corneal anatomy redefined: a novel pre-Descemet's layer (Dua's layer). Ophthalmology 120 1778-1785.

34. Pérez-Santonja JJ, Hervás-Hernandis JM (2006) Queratitis infecciosas: fundamentos, técnicas diagnósticas y tratamiento. Ergon, $278 \mathrm{p}$.

35. Garg A, Sheppard JD, Donnenfeld ED, Friedlaender MH (2007) Clinical Applications of Antibiotics and Anti-Inflammatory Drugs in Ophthalmology, Lippincott Williams \& Wilkins, $598 p$
36. Keay LJ, Gower EW, lovieno A, Oechsler RA, Alfonso EC, et al. (2011) Clinical and microbiological characteristics of fungal keratitis in the United States, 2001-2007: a multicenter study. Ophthalmology 118: 920-926.

37. Quimioterapia SE de (2006) Antimicrobianos en medicina. Sociedad Española de Quimioterapia; $843 \mathrm{p}$

38. Sun CQ, Lalitha P, Prajna NV, Karpagam R, Geetha M, et al. (2014) Association between in vitro susceptibility to natamycin and voriconazole and clinical outcomes in fungal keratitis. Ophthalmology 121: 1495-1500.

39. Benson H (1974) Permeability of the cornea to topically applied drugs. Arch Ophthalmol 91: 313-327.

40. O'Day DM, Head WS, Robinson RD, Clanton JA (1986) Corneal penetration of topical amphotericin B and natamycin. Curr Eye Res 5: 877-882.

41. Behrens-Baumann W, Uter W, Ansorg R (1987) [Experimental studies of local therapy of Candida keratomycosis with amphotericin B]. Klin Monbl Augenheilkd 191: 125-128.

42. Prajna NV, Krishnan T, Mascarenhas J, Rajaraman R, Prajna L, et al. (2013) The mycotic ulcer treatment trial: a randomized trial comparing natamycin vs voriconazole. JAMA Ophthalmol 131: 422-429.

43. Wang B, Wang L, Chen P, Zhang J (2012) Pharmacokinetics of topically applied econazole nitrate nanoparticles in rabbit eye. Chin $\mathrm{J}$ Exp Ophthalmol 30: 677-680.

44. Abbasoğlu OE, Hoşal BM, Sener B, Erdemoğlu N, Gürsel E (2001) Penetration of topical fluconazole into human aqueous humor. Exp Eye Res 72: 147-151.

45. Hariprasad SM, Mieler WF, Lin TK, Sponsel WE, Graybill JR (2008) Voriconazole in the treatment of fungal eye infections: a review of current literature. Br J Ophthalmol 92: 871-878.

46. Lalitha P, Shapiro BL, Srinivasan M, Prajna NV, Acharya NR, et al. (2007) Antimicrobial susceptibility of Fusarium, Aspergillus, and other filamentous fungi isolated from keratitis. Arch Ophthalmol 125: 789-793.

47. Qiu WY, Yao YF, Zhu YF, Zhang YM, Zhou P, et al. (2005) Fungal spectrum identified by a new slide culture and in vitro drug susceptibility using Etest in fungal keratitis. Curr Eye Res 30: 1113-1120.

48. Lalitha P, Sun CQ, Prajna NV, Karpagam R, Geetha M1, et al. (2014) In vitro susceptibility of filamntous fungal isolates from a corneal ulcer clinical trial. Am J Ophthalmol 157: 318-326.

49. Xu Y, Pang G, Gao C, Zhao D, Zhou L, et al. (2009) In vitro comparison of the efficacies of natamycin and silver nitrate against ocular fungi. Antimicrob Agents Chemother 53: 1636-1638.

50. Knowledge Base The antimicrobial Index [Internet]. Knowledge Base The antimicrobial Index.

51. Galarreta DJ, Tuft SJ, Ramsay A, Dart JK (2007) Fungal keratitis in London: microbiological and clinical evaluation. Cornea 26: 1082-1086.

52. Tzatzarakis MN, Tsatsakis AM, Charvalos E, Vakalounakis D (2001) Comparison of in vitro activities of amphotericin, clotrimazole, econazole, miconazole, and nystatin against Fusarium oxysporum. J Environ Sci Health B 36: 331-340.

53. Guinet R, Mazoyer MA (1984) [In vitro comparative study of the sensitivity of Aspergillus to antifungal agents]. Pathol Biol (Paris) 32: 654-657.

54. Jit Sud I, Feingold DS (1975) Detection of agents that alter the bacterial cell surface. Antimicrob Agents Chemother 8: 34-37.

55. Ficha Técnica EXOCIN $3 \mathrm{mg} / \mathrm{ml}$ colirio en solución [Internet].

56. Wong CA, Galvis V, Tello A, Villareal D, Rey JJ (2012) [In vitro antibiotic susceptibility to fluoroquinolones]. Arch Soc Esp Oftalmol 87: 72-78.

57. Bremond-Gignac D, Bremond-Gignac F, Milazzo S (2011) A European Perspective on Topical Ophthalmic Antibiotics: Current and Evolving Options. Ophthalmol Eye Dis 3: 29-43.

58. Felton T, Troke PF, Hope WW (2014) Tissue penetration of antifungal agents. Clin Microbiol Rev 27: 68-88

59. Lorian V (2005) Antibiotics in Laboratory Medicine, Lippincott Williams \& Wilkins, $922 \mathrm{p}$. 